\title{
EFECTO DE UNA QUEMA CONTROLADA SOBRE LA POBLACIÓN MICROBIANA EN SUELOS CON PASTURAS EN LA SAIS TUPAC AMARU - JUNÍN, PERÚ
}

\section{EFFECT OF PRESCRIBED BURNING ON MICROBIAL POPULATIONS OF GRASSLANDS SOILS OF THE TUPAC AMARU SAIS - JUNIN, PERU}

\author{
Diana L. Torres Vargas ${ }^{1}$, Roberto Quiroz Guerra ${ }^{2}$ y Juan Juscamaita Morales ${ }^{3}$,
}

\section{Resumen}

Se evaluó el efecto de la quema controlada sobre las poblaciones de bacterias aerobias, bacterias anaerobias, hongos y dos géneros de Bacterias Libres Fijadoras de Nitrógeno (BLFN, Azotobacter sp. y Azospirillum sp.) en suelos con pasturas de la Sociedad Agrícola de Interés Social Túpac Amaru, Junín. Los muestreos se realizaron desde el final de la época seca (Septiembre del 2001) hasta el inicio de la siguiente época seca (Junio del 2002). La quema se llevó a cabo a inicios del mes de Octubre, empleando la metodología de una quema frontal, a favor del viento. Las características del suelo, como humedad, fósforo, potasio, CIC, CE, cationes, materia orgánica, nitrógeno y $\mathrm{pH}$, no variaron después de realizada la quema. La quema no afectó $(\mathrm{P}>0.05)$ a las poblaciones de bacterias aerobias, bacterias anaerobias y hongos. En los géneros de BLFN aislados, no se observaron variaciones grandes en las muestras obtenidas inmediatamente después de la quema, sin embargo, en los análisis de variancia de los demás muestreos se obtuvo altas variancias para las poblaciones del Cuadrado Sin Quema, siendo mucho menores las variancias en el Cuadrado Quema. La aplicación de fuego en el Cuadrado Quema habría provocado una mayor estabilidad poblacional, mostrando la población de BLFN del Cuadrado Sin Quema una mayor variabilidad espacial.

Palabras clave: Quema controlada, Bacterias Aerobias, Bacterias Anaerobias, Hongos, Azotobacter, Azospirillum, Correlaciones Canónicas.

\begin{abstract}
A study was carried out to evaluate the effects of prescribed burning (head fire) in populations of aerobic bacteria, anaerobic bacteria, fungi and two genus of Nitrogen-fixing bacteria (Azotobacter sp. and Azospirillum sp.) in Junín. Samples were taken from the end of the dry season (September 2001) to the beginning of the following dry season (June 2002). The burning experiment was carried out at the beginning of October (beginning of the rain season), using the Head Fire Burning methodology (it burns in favor of the wind). Characteristics of the soil, humidity, phosphorus, potassium, CEC, EC, cations, organic matter, nitrogen and $\mathrm{pH}$, did not vary after the burning. Burning did not affect aerobic bacteria, anaerobic bacteria and fungi populations. Student's t-test $(\alpha=0.05)$ was used and non significant differences were found between these populations before and after the burning. Regarding Nitrogen-fixing bacteria, great variations in the samples obtained immediately after burning were not observed. In the variance analysis, the No-Burning quadrat showed larger variances than the Burning quadrat. Application of fire in the Burning quadrat would have caused population stability, while the Nitrogen-fixing bacteria of the No-Burning quadrat showed greater spatial variability.

Key words: Prescribed burning, aerobic bacteria, anaerobic bacteria, fungi, Azotobacter, Azospirillum.
\end{abstract}

\section{Introducción}

Las praderas nativas o pastizales en el Perú ocupan un área importante dentro del territorio peruano. Según el Institututo Nacional de Estadística e Informática (1995), mencionado por Chancayauri (1999), tenían una extensión de 15, $679 \quad 873.12$ hectáreas. Estos pastizales se ubican desde los 3500 msnm hasta los $4800 \mathrm{msnm}$ y el $92 \%$ de esta totalidad está en la sierra (Argote, 1999). Debido a la altitud, la complicada topografía y los bajos niveles de fósforo y otros elementos del suelo en estas praderas, la agricultura no puede ser la actividad económica que sustente la población que la habita y el suelo queda relegado a sustentar pastos naturales que permitan una actividad pecuaria extensiva. El manejo adecuado de pastizales es primordial para asegurar la disponibilidad de pastos sanos y palatables todo el año; por ello, periódicamente se realizan "quemas" de estas pasturas con el objeto de permitir el aprovechamiento de la vegetación de piso por el ganado ovino, y rebrotes por el ganado vacuno (ONERN, 1976).

Según Argote (1999), los pastizales peruanos podrían sostener una población ganadera mayor a la 
carga actual; sin embargo, debido a prácticas inadecuadas de manejo de pastizales, se ve afectada la productividad de las especies vegetales aptas para el pastoreo.

El fuego es una fuerza natural en la mayor parte de las comunidades vegetales que existen (Whright \& Bailey, 1982), por eso es indispensable lograr entender la manera como éste afecta al ecosistema.

Entre los pocos trabajos realizados con poblaciones microbianas del suelo, sometidas a quemas, tenemos la investigación realizada por Miller et al. (1955), Neuenschwander (1976) y Jurgensen et al. (1979), mencionados por Wright \& Bailey (1982), quienes observaron que las poblaciones bacterianas declinan rápidamente después de un incendio, pero manifiestan un incremento de 3 a 10 veces el tamaño de su población al primer mes de recuperación. Por otro lado, según Gibbs (1919), mencionado también por Wright \& Bailey (1982), las bacterias nitrificantes tienen umbrales pequeños y son fácilmente exterminadas a temperaturas que van de 53 a $56^{\circ} \mathrm{C}$, están protegidas generalmente por las capas de suelo que se encuentran sobre ellas y las poblaciones son capaces de recuperarse rápidamente después de un incendio.

La temperatura es un factor importante que controla las actividades de las poblaciones de microorganismos del suelo, acelerando la tasa de crecimiento de éstas. Existen reportes de que la quema puede incrementar la temperatura del suelo tiempo después de la quema, favoreciendo de esta manera, que se incrementen las poblaciones microbianas. Hensel (1923), Greene (1935), Weaver \& Roland (1952), Kucera \& Ehrenreich (1962), Scotter (1963) y Peet et al. (1975) (mencionados por Thompson \& Schimel, 1984) sostienen que la temperatura del suelo de una zona quemada es mayor que la de una no quemada, en un rango de 3 a $16^{\circ} \mathrm{C}$.

La humedad que presenta el suelo que es sometido a quemas es también importante, DeBano et al. (1998) sostienen que si en los primeros 5 centímetros la humedad es de $10 \%$, y el suelo es sometido a $70^{\circ} \mathrm{C}$, el calentamiento generado podría matar a aproximadamente el $95 \%$ de las bacterias heterotróficas y a una gran proporción de hongos; mientras que si el suelo está seco, sometido a la misma temperatura provocaría la muerte de menos del $25 \%$ del mismo grupo bacteriano.

Debido a la influencia de la microflora del suelo en el desarrollo de la vegetación, es indispensable conocer lo que las quemas provocan en las poblaciones microbianas, de tal manera que no se dañe a estos organismos, que según Jhoncon \& GutiérrezCorrea (1982) no sólo constituyen el primer nivel trófico, sino que son también responsables de la formación del suelo, de ecosistemas, de la recirculación de elementos químicos y de la energía.
Aunque las quemas de pastizales son un método de manejo muy utilizado en las zonas altoandinas, no existen trabajos que reporten lo que el fuego ocasiona a los microorganismos, por ello, el objetivo principal de este estudio fue evaluar el efecto de las quemas de pastizales en las poblaciones microbianas.

\section{Materiales y Métodos \\ Lugar Experimental}

El trabajo se llevó a cabo en Champacancha, dentro del distrito de Canchayllo, Unidad de Producción Pachacayo de la Sociedad Agrícola de Interés Social Túpac Amaru Ltda. El campo experimental se ubica a $4100 \mathrm{msnm}$. Se delimitaron dos parcelas de aproximadamente $1250 \mathrm{~m}^{2}$ cada una, a las que se denominó Cuadrado Quema (CQ) y Cuadrado Sin Quema (CSQ), la asociación agrostológica es Festuchetum-Calamagrosetum.

\section{Método de Quema}

Aunque las quemas en pastizales altoandinos se realizan principalmente en época seca (Noli, 1992; Vargas, 2002), la quema efectuada para el presente estudio se realizó a inicios de la época de lluvias, para poder obtener una recuperación más rápida de los pastos que fueron quemados al recibir la precipitación, ya que la quema de pastizales puede ser muy desfavorable durante períodos muy secos (Wright \& Bailey, 1982).

El área escogida cumplió con los requisitos para realizar una quema controlada adecuada según Wright \& Bailey (1982), es decir, la cantidad de biomasa (670 a $1120 \mathrm{~kg} / \mathrm{ha}$ ), exposición y pendiente (menor a $20 \%$ ) que permite controlar la intensidad del fuego aplicado.

Antes de la quema, se midieron variables meteorológicas como humedad, dirección e intensidad del viento, para esperar el momento más adecuado de quema. Estas cumplieron con las especificaciones de Wright \& Bailey (1982); la humedad relativa se encontraba de 15 a $25 \%$, la temperatura ambiental de $17^{\circ} \mathrm{C}$ y la velocidad del viento era menor a $32 \mathrm{~km} / \mathrm{h}$.

Se aplicó una variante del método de quema focalizada o "head fire". Se establecieron barreras por remoción de vegetación en el perímetro (mediante el paso de un tractor) y se procedió a la quema. Para evitar que el fuego traspase las barreras, se apagó el mismo con pellejos de carnero mojados. Se contó con brigadas de contención del fuego a lo largo del perímetro, evitando en todo momento, que se propague a la vegetación de las zonas aledañas.

\section{Muestreos y Toma de Muestras}

La quema se realizó el 9 de Octubre del 2001. Se procedió a tomar muestras antes y después de la quema (9 y 10 de Octubre), 29 de Octubre (aproximadamente 2 semanas después de la quema); 12 de Noviembre (aproximadamente un mes después de la quema, inicio de época de lluvias); 12 de Diciembre (dos meses después de la quema, época de 
lluvias); 13 de Febrero; 10 de Abril (fin de época de lluvias) y 11 de Junio (inicio de época seca).

Para cada muestreo se tomaron 6 muestras de suelo (del área de influencia radicular) en cada parcela, CQ y CSQ. Se trabajaron 12 muestras en cada muestreo, extraídas de puntos fijos. De cada muestra se realizó el conteo de poblaciones de Bacterias Aerobias, Bacterias Anaerobias y Hongos. Se obtuvo tajadas de $10 \mathrm{~cm}$ de profundidad por $2 \mathrm{~cm}$ de ancho y $15 \mathrm{~cm}$ de largo.

Para el conteo de poblaciones de BLFN se tomaron 2 individuos completos (raíz y parte aérea) de la gramínea Festuca dolicophylla para componer una muestra de raíces (para aislamiento de Azospirillum sp.) y de rizósfera (para aislamiento de Azotobacter sp.) por cada cuadrado.

Medición de la temperatura del suelo

En una quema controlada de un metro cuadrado de pastizal se colocó termistores a tres profundidades diferentes, a $5 \mathrm{~cm}, 10 \mathrm{~cm}$ y $15 \mathrm{~cm}$ de la superficie, luego se procedió a quemar los pastos. Las lecturas de resistencia de los termistores se tomaron con multímetros. Posteriormente, con las ecuaciones de calibración de cada termistor se obtuvo el valor de temperatura.

Toma de muestra de suelo para el análisis de caracterización y de micro-elementos del suelo

De cada lado del cuadrado que constituía un cuadrado (o parcela), se extrajo 1 muestra de suelo libre de plantas y raíces. Con las 4 submuestras se compuso una muestra única por cuadrado, se mezcló y se guardó aproximadamente 1 kilo para ser llevado al laboratorio de suelos donde se realizaron los siguientes análisis: Textura, Materia Orgánica, Carbonatos, CIC, CE, pH, Na, N, P, K, Ca, Mg y $\mathrm{Al}+\mathrm{H}$.

Análisis Microbiológico

Los análisis fueron conducidos en el Laboratorio de Biorremediación del Departamento de Biología de la UNALM.

Para el aislamiento de Bacterias Aerobias, Bacterias Anaerobias y Hongos, se utilizó medios de cultivo sólidos específicos para cada grupo. Los medios fueron: el medio Glucosa-Peptona-Agar para las Bacterias Aerobias, para las Bacterias Anaerobias el medio Tioglicolato de Brewer y para los hongos el Medio Agar Rosa de Bengala Dicloran Cloramfenicol. (García, 1984).

Las diluciones utilizadas para cada grupo microbiano fueron, $10^{-4}$ y $10^{-5}$ para bacterias aerobias, $10^{-2}$ para bacterias anaerobias y $10^{-3}$ y $10^{-4}$ en el caso de hongos. Se incubó a $28^{\circ} \mathrm{C}$ durante 3 días para las Bacterias Aerobias y Hongos, 6 días para las bacterias anaerobias. Al cabo del tiempo de incubación se procedió al conteo de colonias o unidades formadoras de colonia.

Para los Géneros de BLFN se empleó la técnica del Número Más Probable (NMP), con medios de cultivo líquidos específicos para cada género, Caballero (1985) detalla el medio de cultivo para Azotobacter y Rivas (1993) para Azospirillum. Se trabajó hasta la dilución $10^{-7}$, llevándose a incubación a $28^{\circ} \mathrm{C}$ durante 15 días. La lectura consistió en la observación de viraje en el tubo (cambio de color por acidificación del medio) o la formación de una película en la superficie. El número de bacterias se determinó con la Tabla de Cochran (Lindquist, 1999). Análisis estadístico

Para determinar diferencias estadísticas significativas $(\alpha=0.05)$ entre el tratamiento Quema y Sin Quema, se realizó una Prueba - t para muestras pareadas entre los resultados del análisis poblacional de las muestras tomadas antes de la quema, y las muestras tomadas un día después de la quema.

Se utilizó la prueba del Ratio - F máximo (Hartley, 1950) para las variancias de las poblaciones de los géneros Azotobacter sp. y Azospirillum sp.

Análisis de Componentes Principales y de Correlaciones Canónicas

Para el análisis de la relación entre las poblaciones microbianas y los elementos minerales del suelo, se procedió a discriminar entre las variables redundantes y las que aportan la mayor cantidad de información mediante el análisis de Componentes Principales. Los principales objetivos de este análisis son la reducción de datos y el facilitar la interpretación de los mismos (Johnson, 1998).

Posteriormente se aplicó un análisis de Correlaciones Canónicas a los dos conjuntos de variables y se obtuvo las variables de suelo que estarían explicando la dinámica de la variable respuesta (poblaciones microbianas).

Se realizó el análisis de la correlaciones canónicas según Johnson \& Wichern (1929).

\section{Resultados y Discusión}

Dos semanas después de la quema, la recuperación de los pastos era bastante buena y en dos meses los pastos tenían abundantes rebrotes.

Los pastizales son considerados material altamente inflamable. Para realizar una quema se necesita un mínimo de vegetación de 670 a $1120 \mathrm{~kg} / \mathrm{ha}$ (Wright \& Bailey, 1982). En el campo de experimentación, la disposición de pastos palatables era alta, a comparación del requerimiento de combustible vegetal mínimo para realizar una quema controlada en pastizales. El CQ presentó $4199.92 \mathrm{~kg} / \mathrm{ha}$ y el CSQ tenía $4801.19 \mathrm{~kg} / \mathrm{ha}$.

La quema, que duró aproximadamente 2 horas (hora de inicio 10:00 am), no resultó uniforme debido a que la intensidad y dirección del viento son cambiantes. El CQ quedó dividido en tres áreas, en la parte media del cuadrado la quema fue de intensidad media, mientras que en los extremos se podía apreciar una quema mas intensa. 
La disminución en las poblaciones de Bacterias Aerobias Mesófilas Viables y de Hongos (Figura 1) después de la quema no fue significativa $(\mathrm{P}>0.05)$.

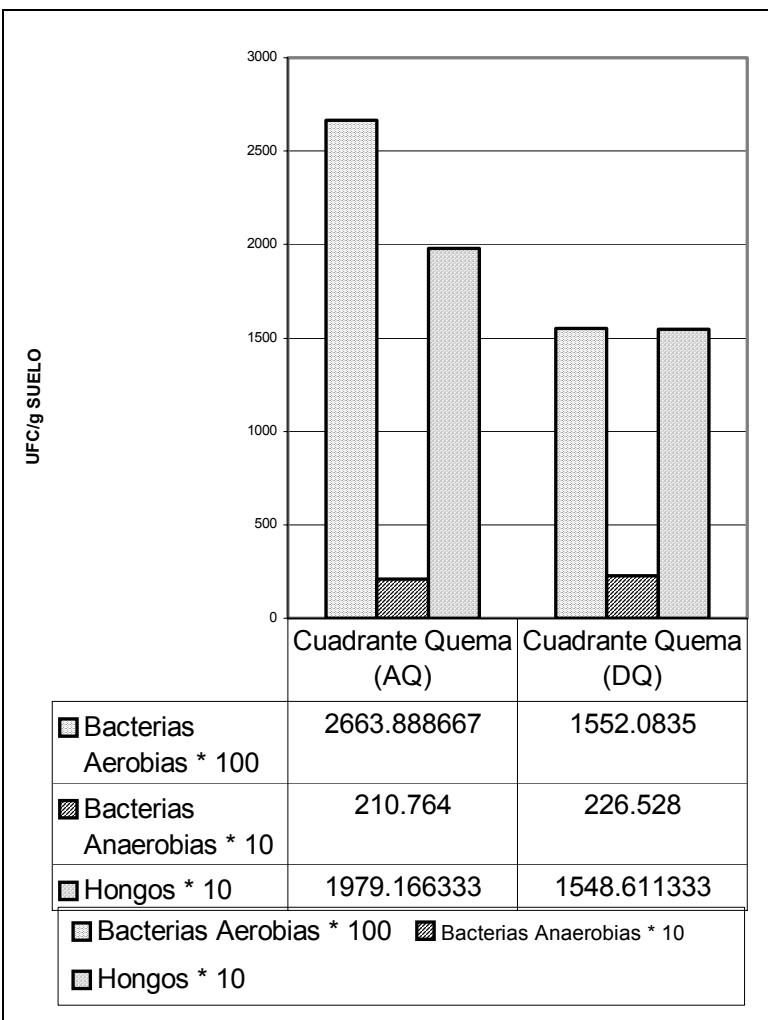

Figura 1. Variación de la población microbiana (\# UFC/g suelo) en el Cuadrado Quema después de ser perturbado mediante una quema controlada.

AQ: Antes de Quema

DQ: Después de Quema

Estos resultados difieren de los reportados en el estudio citado por Wright \& Bailey (1982), en el que Miller et al. (1955) y Jurgensen et al. (1979) trabajaron con poblaciones microbianas del suelo sometidas a quemas. Ellos observaron que las poblaciones bacterianas declinan rápidamente después de un incendio a un valor de casi cero, pero manifiestan un incremento de 3 a 10 veces el tamaño de su población inicial al primer mes de recuperación.

Stendell et al. (1999), observaron con respecto a la población de Micorrizas de un campo experimental de pinos, que ésta disminuyó a un octavo de su tamaño después de una quema controlada.

En el caso de las bacterias anaerobias no existen tampoco diferencias significativas $(\mathrm{P}>0.05)$.

De los análisis de caracterización del suelo, se obtuvo que la quema no afectó ninguna de las propiedades edáficas.

Temperatura del suelo

La temperatura del suelo, como efecto de la quema, incrementó menos que un grado centígrado en la capa superior del suelo (Figura 2). Esta temperatura es similar a la obtenida por Chancayauri (1999) y Argote (1999) en suelos de otra zona de pastizales de puna. Se puede inferir que la quema controlada no incrementa sustancialmente la temperatura del suelo y por ende, no se espera tener efectos negativos sobre la microflora del suelo.

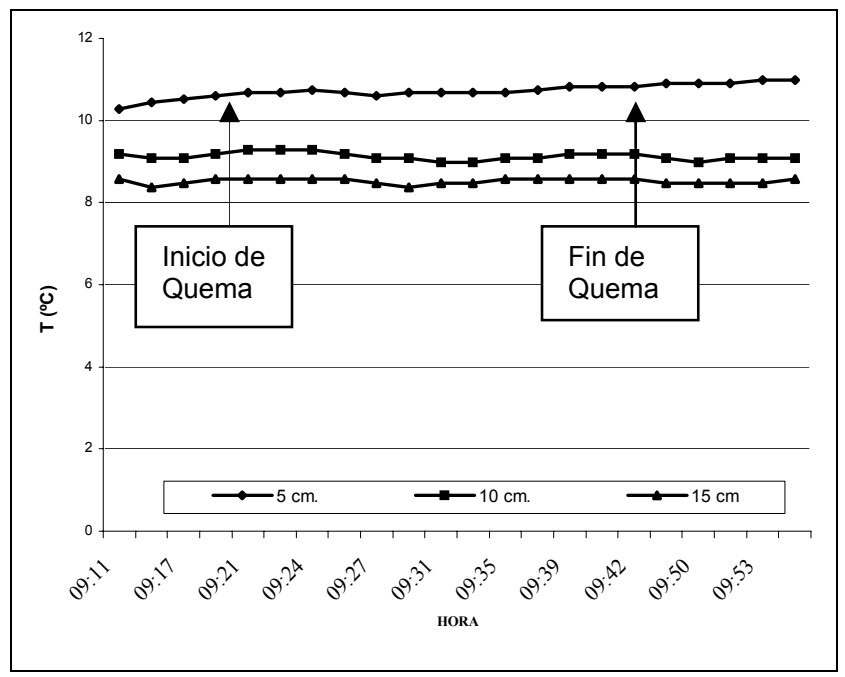

Figura 2. Temperatura $\left({ }^{\circ} \mathrm{C}\right)$ del suelo a 5,10 y $15 \mathrm{~cm}$ de profundidad durante una quema de la vegetación.

Porcentaje de Humedad del Suelo

La humedad del suelo varió entre 22 y $35 \%$ (Figura 3). Los niveles de humedad del suelo después de la quema no llegan a valores que indiquen que el suelo ha disminuido su capacidad para retener humedad (DeBano et al., 1998).

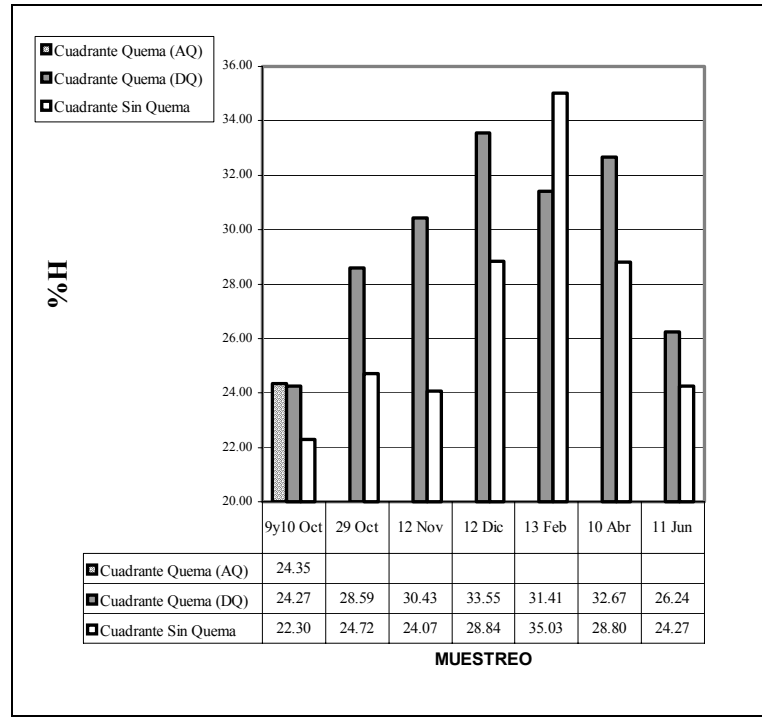

Figura 3. Porcentaje Promedio de Humedad del Suelo (a $10 \mathrm{~cm}$ de profundidad) en los Cuadrados Quema y Sin Quema, Champacancha.

AQ: Antes de Quema

DQ: Después de Quema 


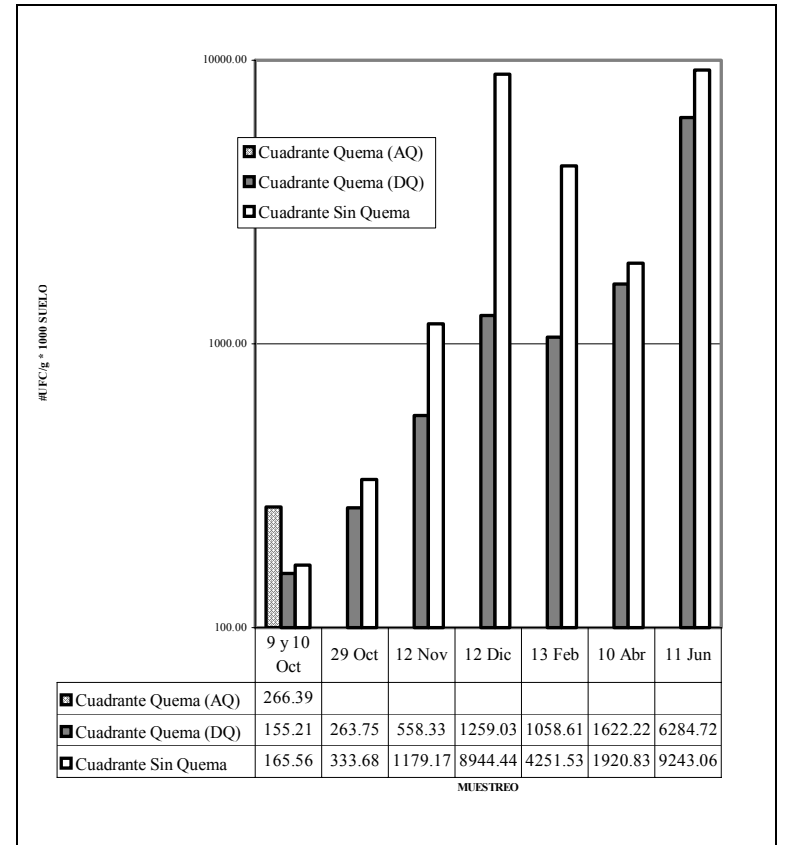

Figura 4. Promedio poblacional de Bacterias Aerobias (\#UFC/g suelo * 1000) en los cuadrados Quema y Sin Quema.

AQ: Antes de Quema

DQ: Después de Quema

Dinámica de las Bacterias Aerobias, Bacterias Anaerobias y Hongos a lo largo del año

Las variaciones poblacionales que pueden observarse en los muestreos posteriores a la quema se deben a la dinámica estacional de estas poblaciones, pues no se observó una variación significativa en el tamaño poblacional después de la perturbación realizada en el área. Las poblaciones de ambos cuadrados (CQ y CSQ) presentan las mismas tendencias en casi todos los muestreos. (Figuras 4, 5 y $6)$.

En suelos de puna en la misma unidad de producción de la SAIS Túpac Amaru, Pahuara \& Zúñiga (2001) trabajando en suelos sembrados con pastos cultivados encontraron que la población varió de casi $10^{6}$ a $11 * 10^{8}$ ufc/g. suelo. Los valores poblacionales de bacterias aerobias de Champacancha llegan a encontrarse dentro de estos rangos.

Pahuara \& Zúñiga (2001), en el experimento llevado a cabo en la Unidad Productiva de Pachacayo, reportaron valores poblacionales de hongos que fluctuaban de casi $10^{4}$ a $10^{6} \mathrm{ufc} / \mathrm{g}$ suelo. Los valores obtenidos en Champacancha van de $5.5 * 10^{3}$ a $7.9 *$ $10^{4} \mathrm{ufc} / \mathrm{g}$. suelo (rango considerado de los valores de ambos cuadrados experimentales) y también se encontrarían dentro del rango de Pahuara \& Zúñiga.

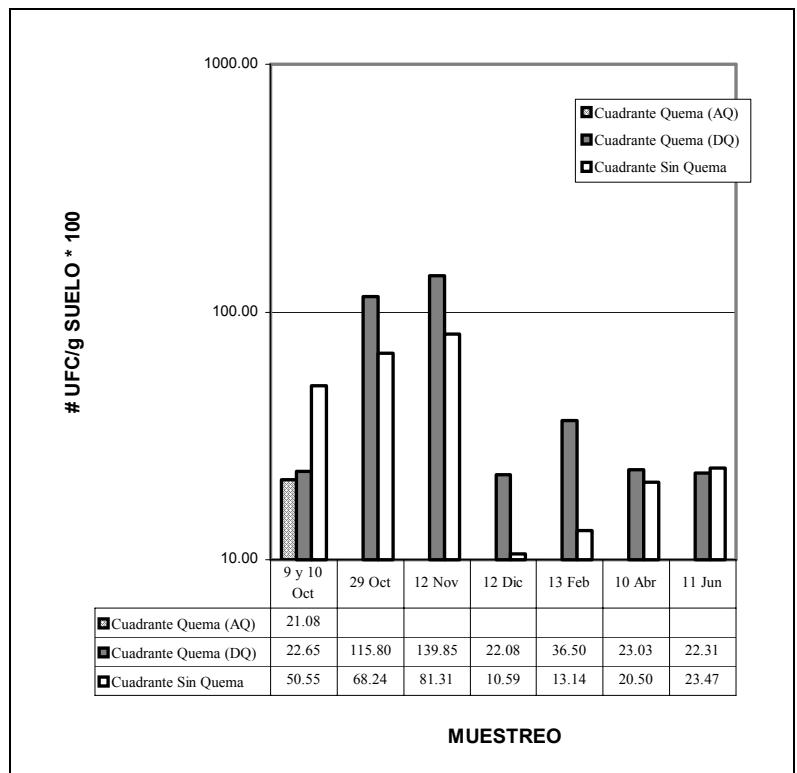

Figura 5. Promedio poblacional de Bacterias Anaerobias (\# UFC/g suelo *100) en los Cuadrados Quema y Sin Quema

AQ: Antes de Quema

DQ: Después de Quema

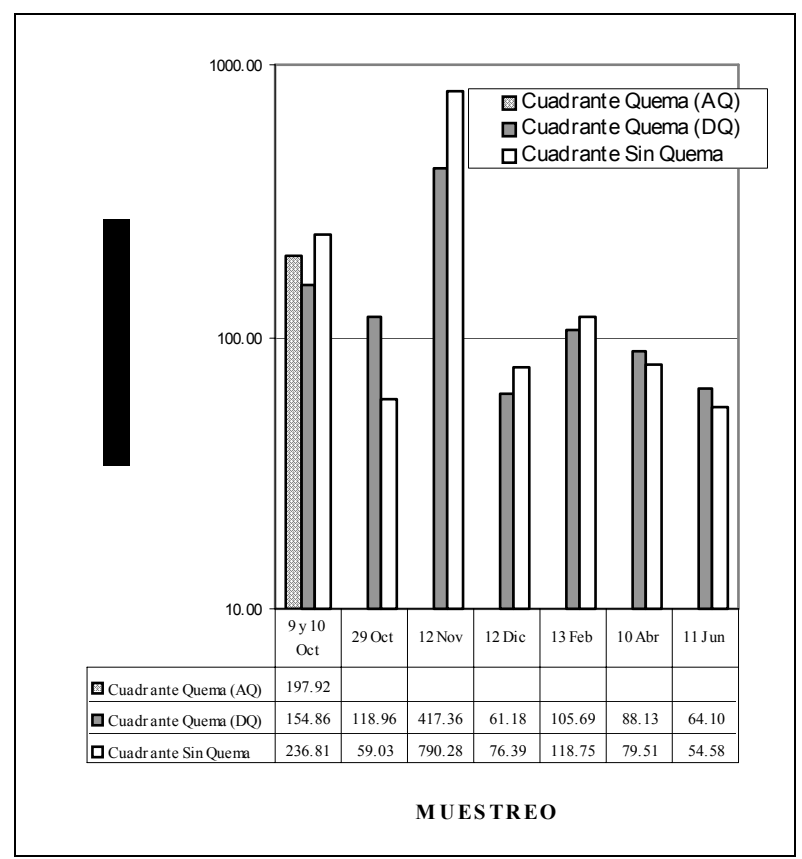

Figura 6. Promedio poblacional de Hongos (UFC/g suelo * 100) en los cuadrados Quema y Sin Quema. AQ: Antes de Quema

DQ: Después de Quema

Correlaciones Canónicas entre los elementos minerales y las poblaciones microbianas

El análisis de correlaciones canónicas para Champacancha mostró que en el CQ las dos primeras relaciones canónicas explican el $91.4 \%$ de la variancia total. La tercera correlación canónica aporta un $8.6 \%$ de la variabilidad total (Tabla 1). 


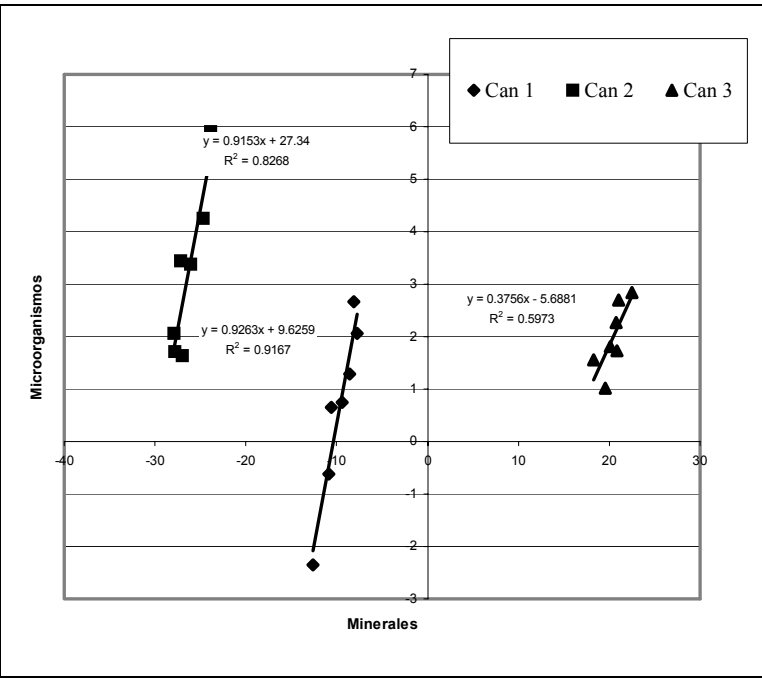

Figura 7. Influencia de las Propiedades Edáficas sobre las Poblaciones Microbianas explicada por el Análisis de Correlaciones Canónicas, Cuadrado Quema.

Tabla 1. Correlaciones Canónicas y Eigenvalues para las variables analizadas del Cuadrado Quema, Champacancha.

\begin{tabular}{|r|r|r|r|r|r|}
\hline $\begin{array}{c}\text { Cuadrado } \\
\text { Quema }\end{array}$ & $\begin{array}{c}\text { Correlación } \\
\text { Canónica }\end{array}$ & \multicolumn{3}{|c|}{$\begin{array}{c}\text { Valores Propios de Inv(E)*H } \\
\text { = CanRsq/(1-CanRsq) }\end{array}$} \\
\hline & & $\begin{array}{l}\text { Valores } \\
\text { Propios }\end{array}$ & Diferencia & Proporción & Acumulado \\
\hline $\mathbf{1}$ & 0.841316 & 2.4225 & 0.7573 & 0.5416 & 0.5416 \\
\hline $\mathbf{2}$ & 0.790439 & 1.6652 & 1.2803 & 0.3723 & 0.9139 \\
\hline $\mathbf{3}$ & 0.527196 & 0.3849 & & 0.0861 & 1 \\
\hline
\end{tabular}

La primera correlación canónica (Figura 7), muestra que el potasio, el $\mathrm{pH}$ y el sodio son las variables que estarían influyendo más en la dinámica de las Bacterias Aerobias. La diferencia en el sentido o dirección de los coeficientes canónicos (Tabla 2) nos da la idea de que se trata de variables detrimentales para el crecimiento de las bacterias aerobias. El pH de Champacancha es ácido y esto no favorece el crecimiento de este grupo bacteriano, que se encuentra mayormente adaptado a condiciones de $\mathrm{pH}$ neutro a alcalino (Atlas \& Bartha, 2002; Madigan et al., 1997). En cuanto al Potasio, éste es un importante cofactor en algunas reacciones enzimáticas, aún en algunas que están relacionadas con la síntesis de proteínas (Atlas \& Bartha, 2002; Madigan et al., 1997). Basta observar la composición química de los componentes estructurales de algún organismo para darnos cuenta de los elementos limitantes para éste. En los microorganismos el potasio es uno de ellos y los valores de nivel medio a bajo que presenta el suelo de Champacancha pueden ser uno de los principales limitantes para estas poblaciones microbianas.
Tabla2. Coeficientes Canónicos para los dos conjuntos de variables analizados en el Cuadrado Quema, Champacancha.

\begin{tabular}{|c|c|c|c|}
\hline \multicolumn{4}{|c|}{$\begin{array}{c}\text { Coeficientes Canónicos Estandarizados para el Conjunto de } \\
\text { Variables } 1\end{array}$} \\
\hline & V1 & V2 & V3 \\
\hline C\#E\# & 0.1212 & -0.5698 & 0.3197 \\
\hline PH & -0.4238 & -0.3729 & 0.0862 \\
\hline MO & 0.0052 & -0.2068 & 0.9807 \\
\hline $\mathbf{P}$ & -0.2387 & -0.1566 & 0.0553 \\
\hline $\mathbf{K}$ & -0.4539 & 0.263 & 0.2554 \\
\hline CIC & 0.3658 & 0.3752 & -0.2208 \\
\hline $\mathrm{Ca}+2$ & 0.4391 & -0.3934 & -0.4164 \\
\hline $\mathrm{Mg}+2$ & -0.1362 & -0.6604 & 0.1064 \\
\hline $\mathbf{K}+$ & -0.0266 & 0.2904 & 0.0648 \\
\hline $\mathrm{Na}+$ & -0.4163 & -0.2673 & -0.9441 \\
\hline $\mathrm{Al} 3++\mathbf{H}+$ & 0.3514 & 0.4214 & -0.6277 \\
\hline \multicolumn{4}{|c|}{$\begin{array}{c}\text { Coeficientes Canónicos Estandarizados para el Conjunto de } \\
\text { Variables 2 }\end{array}$} \\
\hline & W1 & W2 & W3 \\
\hline AEROBIA & 0.6797 & 0.6946 & 0.4304 \\
\hline ANAERO & -0.2922 & 0.6629 & -1.0621 \\
\hline HONGOS & -0.3648 & 0.2464 & 1.2736 \\
\hline
\end{tabular}

Las poblaciones de bacterias anaerobias y hongos presentaron pesos negativos en los coeficientes canónicos, ello implica que en el momento en que una o ambas poblaciones aumentaran, el valor de la variable canónica tendería a ser negativa. Esto fue lo que sucedió en los muestreos 2 y 4 , donde las poblaciones de bacterias anaerobias y hongos dominaron respectivamente, produciendo valores canónicos negativos para la variable denominada microorganismos. Esta respuesta se puede explicar por el pH alto después de la quema (muestreo 2, favoreciendo así a las bacterias anaerobias) y bajo en el muestreo 4, esto favoreció a la población de hongos.

La segunda correlación canónica presenta al Magnesio y a la Conductividad Eléctrica como las variables más importantes para las poblaciones de Bacterias Aerobias y Anaerobias. La función que desempeña el Magnesio es de estabilización de ribosomas, membranas celulares, ácidos nucleicos y también para la actividad de muchas enzimas (Madigan et al., 1997). Según Jentschke et al. (2001), los suelos ácidos presentan deficiencias de Magnesio, hecho que pudimos comprobar en la lectura de los análisis de suelos de nuestra área de estudio. Además, los valores de Conductividad Eléctrica fueron bajos en todos los muestreos por la falta de sales en el medio. 
La tercera correlación canónica arroja que la población de hongos estaría siendo afectada principalmente por la materia orgánica. La relación de estas variables es directa y los hongos serían los que principalmente estarían aprovechando la alta cantidad de materia orgánica disponible en la zona. En su condición de heterótrofos, la descomposición de la materia orgánica es una actividad importante para los hongos.
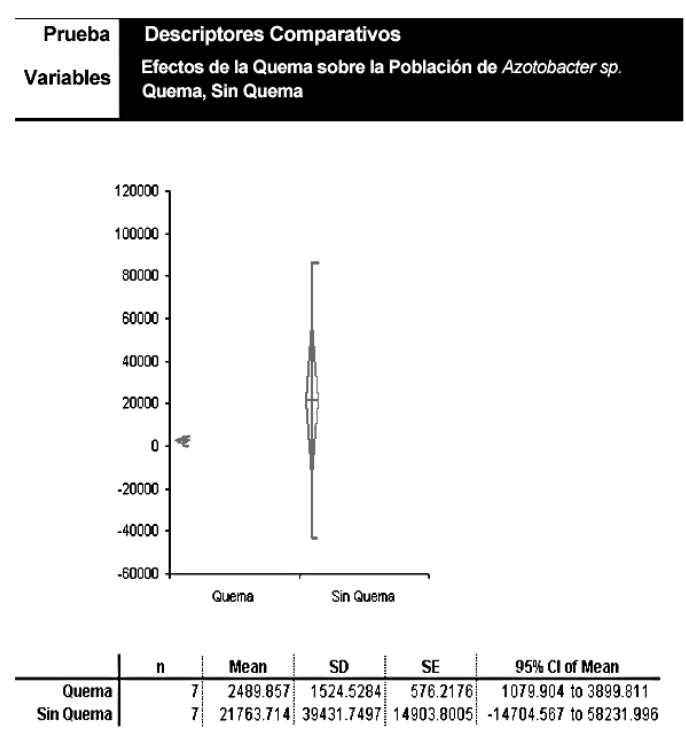

Figura 8. Medida del Désvío de las Medias para la Población de Azotobacter sp. en los cuadrados Quema y Sin Quema.
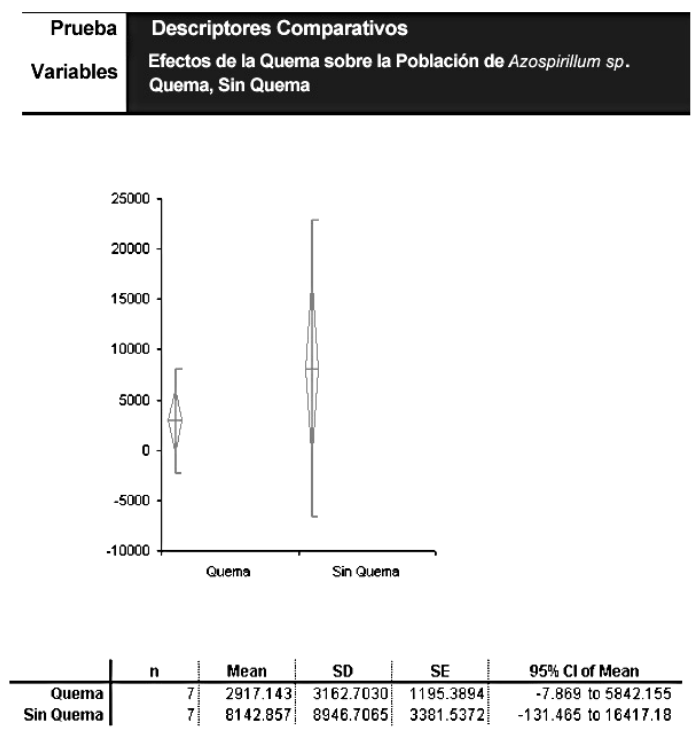

Figura 9. Medida del Desvío de las Medias para la Población de Azospirillum sp. en los cuadrados Quema y Sin Quema.
Seguimiento Muestral Para las Poblaciones de Azotobacter sp. y Azospirillum sp.

Al observar los datos del muestreo correspondiente a la realización de la quema, la población de bacterias del género Azotobacter sp. no sufrió ninguna variación. Por otro lado, la población de Azospirillum sp. muestra un incremento que no es significativo para considerar la quema como un elemento que favorezca el crecimiento poblacional de este género.

Al analizar los resultados obtenidos en los demás muestreos, la prueba de variancias mostró que existe una gran variabilidad en ambos cuadrados, pero es mucho mayor en la población aislada del CSQ que en la del CQ, para ambos géneros.

La diferencia poblacional entre los cuadrados Q y SQ es menor para el género Azospirillum que para Azotobacter, probablemente debido a la naturaleza del hábitat de Azospirillum, que al encontrarse en los rizoplanos de las raíces, se encuentra de alguna forma "más protegido" de las perturbaciones que ocurran en su hábitat.

Los límites de confianza (inferiores y superiores) para ambas poblaciones son extremos (Figuras 8 y 9). El límite inferior para las poblaciones de ambos géneros de BLFN ha sido considerado cero cuando resultó ser un número negativo, ya que esto no es biológicamente posible. Para ambos géneros la variabilidad es demasiado alta como para poder inferir la media y la variancia de la población en un muestreo posterior con los estimativos obtenidos.

La mayor variabilidad encontrada en las poblaciones de los géneros Azotobacter sp. y Azospirillum sp. en el CSQ podría deberse a que este cuadrado permaneció intacto, sin perturbar. En el CSQ la sucesión ha continuado y existen secciones en las que las plantas son maduras y sus raíces hospedan una mayor cantidad de bacterias. Plantas más jóvenes, resultado de procesos de sucesión, aparecen como puntos menos poblados o invadidos. En el CQ, las plantas quemadas regresaron a un estadío sucesional inicial de manera abrupta. La capacidad de ser colonizadas por bacterias es la misma para todas las plantas de ese suelo, debido a ello, la variabilidad hallada es menor.

\section{Conclusiones}

En resumen, los resultados obtenidos indican que la quema de pastizales no parece tener un efecto significativamente negativo sobre los microorganismos del suelo, bajo la condición experimental conducida. Los elementos minerales y las características del suelo tampoco se vieron afectadas por la quema controlada realizada en la zona.

\section{Agradecimientos}

Al Dr. Carlos León-Velarde por la oportunidad y la ayuda brindadas para realizar este trabajo. A 
Manuel Torres Vargas, Javier Osorio, Alberto García, Ivonne Valdizán, Yasmín Raygada, Alex García, Raymundo Gutiérrez, Guido Yactayo, Mónica Maldonado, Liz Castañeda y todos los estudiantes de Biología que colaboraron en los viajes de campo.

Este proyecto fue financiado por el "Systemwide Livestock Programme SLP" a través del proyecto "Enhancing Livestock Productivity while Protecting Mountain Ecosystems" manejado por el Centro Internacional de la Papa.

\section{Literatura citada}

Argote G. 1999. Respuesta de la producción primaria, composición florística y valor nutritivo de pastizales dominados por Calamagrostis antoniana y Festuca dolicophylla a la quema prescrita frontal. Especialidad de Producción Animal. Tesis para optar el Grado de Magister Scientiae. Universidad Nacional Agraria La Molina. Lima, Perú.

Atlas R. \& Bartha R. 2002. Ecología microbiana y Microbiología ambiental. Prentice Hall, Segunda Edición.

Caballero C. 1985. Evaluación del coeficiente Rizósfera - Suelo (R/S) en el trigo (Triticum durum "Estaquilla"), referido a Bacterias Libres Fijadoras de Nitrógeno (BLFN). Tesis para optar el Título de Ingeniero Agrónomo. UNALM.

Chancayauri R. 1999. Dinámica de la producción primaria, composición florística y valor nutritivo de pastizales dominado por Dolychophylla y Calamagrostis vicunarum en respuesta a la quema prescrita frontal. Tesis para optar por el grado de Magister Scientiae de la Especialidad de Producción Animal. UNALM.

DeBano L., Neary D. \& Ffolliott P. 1998. Fire's Effects on Ecosystems. John Wiley \& Sons, c1998.

García A. 1984. Experimentos en Microbiología del Suelo. México, Editorial Continental. pp;45-51, 71-73.

Hartley H. 1950. The Maximum F-Ratio as a short-cut test for Heterogeneity of Variance. Biometrika. 37: 308-312.

Jentschke G., Drexhage M., Fritz H-W., Fritz E., Schella B., Lee D-H., Gruber F., Heimann J., Kuhr M., Schmidt J., Schmidt S., Zimmermann R. \& Godbold D.L. 2001. Does soil acidity reduce subsoil rooting in Norway spruce (Picea abies)?. Plant and Soil. 237 (1): 91-108, Kluwer Academic Publishers.

Jhoncon J. \& Gutiérrez-Correa M. 1982. Estudio Microecológico en suelos de las Lomas de Lachay. II.- Microhongos. Publicación del Centro de Zonas Áridas. : 81-86.
Johnson D. 1998. Métodos Multivariados Aplicados al Análisis de Datos. International Thomson Editores.

Johnson R. \& Wichern D. 1992. Applied Multivariate Statistical Analysis. Prentice-Hall International, Inc. Third Edition.

Jones J. \& Richards B. 1977. Effects of reforestation on turnover of $15 \mathrm{~N}$ - labeled nitrate and ammonium in relation to changes in soil microfauna. Soil Biol. Biochem. 9: 383-392.

Lindquist J.A. 1999. General Microbiology: a Laboratory Manual, third edition. McGrawHill/Primis Custom Publishing. ISBN 0-07235906-4.

Madigan M., Martinko J. \& Parker J. 1997. Brock Biología de los Microorganismos. Prentice Hall, Octava Edición.

Noli C. 1992. La quema de pastos naturales. Revista del INIAA, Año 4. (13): 36.

ONERN (Oficina Nacional de Evaluación de Recursos Naturales). 1976. Inventario y Evaluación de los Recursos Naturales de la SAIS “Túpac Amaru”. ONERN.

Pahuara D. \& Zúñiga D. 2001. Efecto del Fósforo sobre la Población Microbiana en Suelos con Pasturas en la Zona Altoandina de Junín. Ecología Aplicada. 1 (1): 57-64.

Rivas F. 1993. Efecto Asociativo de Azospirillum sp. con Rhizobium leguminosarum sobre la nodulación y rendimiento de materia seca del Haba (Vicia faba L). Tesis para optar el grado de Magister Scientiae. Especialidad de Suelos. UNALM.

Stendell E., Horton T. \& Bruns T. 1999. Early effects of prescribed fire on the structure of the ectomycorrhizal fungus community in a Sierra Nevada ponderosa pine forest. Mycological Research. Cambridge University Press Copyright (C) The British Mycological Society. 103: 13531359.

Thompson N. \& Schimel D. 1984. Fire Effects on Nitrogen Mineralization and Fixation in Mountain Shrub and Grassland Communities. Journal of Range Management. 37 (5): 402-405.

Vargas O. 2002. Disturbios, patrones sucesionales y grupos funcionales de especie en la interpretación de matrices de paisaje en los páramos. PerezArbelaezia No. 13. pp: 73-79.

Wright H. \& Bailey A. 1982. Fire Ecology. John Wiley \& Sons, Inc.

Zúñiga D. \& Gutiérrez-Correa M. 1982. Diazótrofos libres en la rizósfera de Sicyos baderoa Lomas de Lachay, Lima, Perú. Zonas Aridas. JulioDiciembre No. 2. Publicación del Centro de Investigaciones de Zonas Aridas. : 79-86. 
${ }^{1}$ Egresada de la UNALM (Facultad Ciencias-Biología), becaria del Centro Internacional de la Papa. Av. La Molina 1895, La Molina, Perú.

Apartado 1558, Lima 12, Perú.

Dirección electrónica: dianaltv@yahoo.com

${ }^{2}$ Líder, División de Manejo de Recursos Naturales del Centro Internacional de la Papa. Av. La Molina 1895, La Molina, Perú.

Apartado 1558, Lima 12, Perú.

Dirección electrónica: r.quiroz@cgiar.org

${ }^{3}$ Profesor Asociado de la Facultad de Ciencias de la UNALM.

Av. La La Molina s/n, La Molina, Perú.

Apartado 12-056, Lima 12, Perú.

Dirección electrónica: jjm@lamolina.edu.pe 